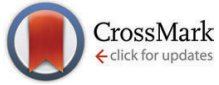

Cite this: J. Mater. Chem. C, 2016, 4,863

Received 26th November 2015, Accepted 20th December 2015

DOI: $10.1039 / c 5 t c 03989 d$

www.rsc.org/MaterialsC

\section{A model for carbon incorporation from trimethyl gallium in chemical vapor deposition of gallium nitride $\uparrow$}

\author{
Örjan Danielsson, * Xun Li, Lars Ojamäe, Erik Janzén, Henrik Pedersen and \\ Urban Forsberg
}

\begin{abstract}
Semi-insulating buffer layers are utilized to prevent leakage currents in Gallium Nitride (GaN) high power semiconductor devices. To make the GaN material semi-insulating, it can be doped with carbon. Carbon is inherently present in the process for producing GaN thin films by chemical vapor deposition (CVD), through the use of trimethyl gallium (TMGa) as a precursor. TMGa decomposes in the gas phase, releasing its methyl groups, which act as a carbon source for doping. It is previously known that carbon doping levels can be controlled by tuning CVD process parameters, such as temperature, pressure and precursor flow rates. However, the mechanism for carbon incorporation from TMGa is not yet understood. In this paper, a reactor independent model for predicting carbon incorporation from TMGa in GaN layers grown by CVD is proposed. The model is based on ab initio quantum chemical calculations of molecular adsorption and reaction energies. Computational Fluid Dynamics, including a chemical kinetic model for the decomposition of the precursors and reactions in the gas phase, is used to calculate gas mixture composition under realistic process conditions. These results are used together with the proposed model to obtain carbon doping concentrations as well as growth rates, varying inlet $\mathrm{NH}_{3} /$ TMGa ratios (157-625) and temperature $\left(800-1100{ }^{\circ} \mathrm{C}\right)$. The model predictions are then correlated with measurements with good agreement. It is concluded that the contribution of gallium to the $\mathrm{GaN}$ layer shifts from $\mathrm{GaCH}_{3}$ at low temperatures to atomic $\mathrm{Ga}$ at higher temperatures. In the same way there is a shift in carbon doping contribution, from $\mathrm{CH}_{3}$ at low temperatures to $\mathrm{C}_{2} \mathrm{H}_{x}$ at higher temperatures.
\end{abstract}

\section{Introduction}

Gallium nitride (GaN) is a stable, direct bandgap semiconductor that has been used in bright, blue LED devices for several decades, which was highlighted with the Nobel Prize in Physics in 2014. GaN is also a principal material for the fabrication of high-power and high-frequency devices. One of its unique and important characteristics is the fact that GaN can operate at elevated temperatures, making it an ideal material for power amplifiers. GaN has the possibility to form alloys with the other group 13 nitrides (also known as III-nitrides), particularly aluminum nitride (AlN) and indium nitride (InN) which also have very favorable electronic properties positioning the group 13 nitrides as key materials for future electronic devices for applications ranging from solid state lighting to high frequency telecommunication.

Department of Physics, Chemistry and Biology, Linköping University, SE-58183 Linköping, Sweden. E-mail: orjan.danielsson@liu.se

$\dagger$ Electronic supplementary information (ESI) available. See DOI: 10.1039/c5tc03989d
Regardless of the application, the performance of GaN based devices is highly affected by impurities incorporated into the material during processing. Sometimes impurities are wanted, for example as dopants to control the material's electrical conductivity, and sometimes impurities can have severe negative effects on device performance.

A crucial aspect in the realization of GaN based devices is the possibility to synthesize thin layers of these materials uniformly over large areas. The most common approach to achieve this with controlled thicknesses is to use chemical vapor deposition (CVD), which is a process where the layers are formed through surface chemical reactions between molecules containing the atoms needed for the target film, in this case nitrogen and aluminum, gallium or indium. The standard chemical route for CVD of the group 13 nitrides is to use trimethyl-metal complexes $\left(\mathrm{M}\left(\mathrm{CH}_{3}\right)_{3}\right.$, where $\mathrm{M}=\mathrm{Al}, \mathrm{Ga}$ or In) in combination with ammonia $\left(\mathrm{NH}_{3}\right)$. Even though CVD of $\mathrm{GaN}$ can be regarded as a mature synthesis route for GaN films, the mechanisms for incorporation of impurities into the material is still very much unknown. Understanding and controlling 
impurity incorporation is of highest importance in order to further advance the development of semiconductor technology based on the group 13 nitrides.

One of the most important and common impurities in GaN is carbon, which can be utilized to obtain a semi-insulating material ${ }^{1,2}$ but also acts as a p-type dopant. ${ }^{3}$ Carbon is inherently present in CVD of GaN from the use of trimethyl gallium (TMGa) as a precursor. ${ }^{4}$ It can be noted that the main alternative to TMGa is triethyl gallium (TEGa) which will also form hydrocarbon species in the gas phase. ${ }^{5}$ The carbon free precursors $\mathrm{GaCl}$ and $\mathrm{GaCl}_{3}$ are generally avoided in CVD of $\mathrm{GaN}$ as their use may lead to the formation of solid particles of $\mathrm{NH}_{4} \mathrm{Cl}$, which will destroy the GaN layers. Also, high amounts of solid $\mathrm{NH}_{4} \mathrm{Cl}$ downstream from the reaction cell will badly affect the vacuum system and pumps.

At the temperatures used for GaN CVD, 600-1100 ${ }^{\circ} \mathrm{C}$, TMGa decomposes in the gas phase releasing its methyl groups; however the mechanism for the incorporation of carbon from TMGa is not yet understood. It is tempting to think that a released $\mathrm{CH}_{3}$ will be very reactive towards the GaN surface, but it must then be remembered that GaN CVD is done in a mixture of hydrogen and nitrogen in which the TMGa is diluted on the order of 1000 times and that the methyl groups released in the gas phase therefore likely will react with hydrogen to form methane, which is very unreactive due to its high symmetry. It is known experimentally that the carbon content in the GaN layers can be controlled to some degree by varying process conditions such as temperature, $\mathrm{NH}_{3} / \mathrm{TMGa}$ ratio and pressure. ${ }^{4,6,7}$ However, changing process parameters to control impurity incorporation may lead to non-optimal conditions for the actual GaN growth, which in turn may lead to layers with rough morphology or bad thickness and doping uniformity. Separate carbon precursors have therefore been suggested for applications where a controlled amount of carbon is desired in the layers. ${ }^{8}$ For applications where essentially carbon free GaN is desired an alternative Ga precursor is most likely needed. From a better understanding of how carbon from the Ga precursor is incorporated into GaN, new precursors can be designed that may still contain carbon atoms in the ligands but with ligands designed to give a precursor decomposition that may lead to significantly lower carbon incorporation.

In this paper we use thermochemical and quantum chemical modelling of the gas phase and surface chemistry, respectively, to form a better understanding of the CVD chemistry of GaN. Our modelling is then combined with the experimental results of carbon incorporation into GaN CVD to propose an empirical model for the carbon incorporation chemistry in GaN CVD layers.

\section{Methods}

Gas-phase species concentrations are calculated by chemical kinetic simulations using computational fluid dynamics, while surface reaction energies are calculated by quantum chemistry methods. Experimental data, obtained in a hot-wall
CVD system, are used for validation of the model. The details of the computational and experimental methods are given below.

\subsection{Chemical kinetic simulations}

The development of the CVD gas mixture composition with time under relevant process conditions was studied by Computational Fluid Dynamics (CFD) using a finite-rate chemical kinetic model for the decomposition of precursors, and for reactions between the resulting products. The chemical kinetic model consists of 220 elementary reaction steps for hydrocarbon decomposition and reactions with hydrocarbon molecules containing up to four carbon atoms. ${ }^{9-15}$ It is likely that the number of relevant reaction steps are less, but the focus of the present study is to investigate the doping mechanism of GaN and not to optimize a gas-phase reaction modeling scheme, and therefore the gas-phase reaction scheme is kept large not to limit the number of possible species or to produce "short cuts" to more abundant species through a simplified scheme. For decomposition of TMGa, the model from Sengupta et al. was used. ${ }^{16}$ The formation of a Lewis-adduct between TMGa and $\mathrm{NH}_{3}$, and subsequent decomposition to a three membered ring compound, $\left[\mathrm{Ga}\left(\mathrm{CH}_{3}\right)_{2} \mathrm{NH}_{2}\right]_{3}$, has in the past been discussed in the GaN literature, and it has been suggested as a main pathway to GaN growth. ${ }^{17-19}$ While this might be the case at low temperatures $(<1000 \mathrm{~K})$, experimental studies have shown no evidence of adduct formation or its decomposition products at the high temperatures typically used to grow high quality GaN. $^{20,21}$ Sengupta $^{22}$ used DFT and QRRK theories to calculate reaction rate constants for the adduct related reactions and found negligible concentrations of the monomer $\mathrm{Ga}\left(\mathrm{CH}_{3}\right)_{2} \mathrm{NH}_{2}$, indicating an almost zero possibility to form the trimer ring compound, further supporting the experimental findings. Thus, in the gas-phase model used here, reactions leading to the trimer ring compound are excluded, while reactions leading to the formation of the adduct, as well as its other decomposition products are included. ${ }^{16}$ It was further assumed in the chemical model that $\mathrm{N}_{2}$ and $\mathrm{NH}_{3}$ do not react with hydrocarbons to form $\mathrm{N}-\mathrm{C}$ species. Reaction pathways to form such species were e.g. studied by Zhu et al., ${ }^{23}$ who showed that the probability to form $\mathrm{N}-\mathrm{C}$ bonds, for example by reactions between $\mathrm{CH}_{3}$ and $\mathrm{NH}_{3}$, is reduced due to the much more probable reaction $\mathrm{CH}_{4}+\mathrm{NH}_{2} \rightarrow \mathrm{CH}_{3}+\mathrm{NH}_{3}$. All reaction steps used in the gas-phase kinetic model and their respective rate constants are provided in the ESI. $\dagger$

Since we are using CFD, the whole CVD reactor could, in principle, be modeled and used in the simulations. However, the complex design of the real CVD reactor would lead to very time consuming simulations only for solving the flow inside the chamber. Adding heat and chemical models increase the complexity even further. Alternatively, several simplifications would be needed which inevitably introduce large uncertainties in the results. Also, process parameters and conditions differ between different reactor designs and the purpose here is not to develop a model adapted to a specific reactor setup, but rather to study the fundamentals of carbon incorporation into GaN. Therefore a more general reactor geometry is chosen here. 
A so-called plug flow reactor ${ }^{24}$ was used as the model geometry for the simulations. In this type of reactor the flow profile is completely flat (a 'plug'), which together with imposed isothermal conditions makes the axial distance of the reactor equal to a time coordinate of the reacting system. The results from the CFD simulations could then be analyzed at a time corresponding to the residence time of the gas in the real CVD reactor. In the study this time was set to $0.6 \mathrm{~s}$, estimated from a more detailed CFD simulation of the CVD system used for the experimental part.

\subsection{Quantum chemistry}

Molecular quantum-chemical calculations were performed for models of the GaN surface with different adsorbates. From these computations, data for the adsorption and activation energies were obtained, which were subsequently used as input for kinetic simulations. The program Gaussian $09^{25}$ was utilized for the calculations, in which the hybrid density functional $\mathrm{B} \mathrm{LYP}^{26}$ in combination with the 6-31G(d,p) basis $\operatorname{set}^{27}$ was used. This methodology is the same as that used in our earlier studies of GaN. ${ }^{28,29}$

The GaN (0001) surface was simulated by a cluster model, cut out from the crystal structure, ${ }^{30}$ that consisted of $24 \mathrm{Ga}$ and $24 \mathrm{~N}$ atoms forming two GaN layers perpendicular to the [0001] direction (a cluster size that was also studied in ref. 28). Dangling bonds at all surface planes were saturated by capping $\mathrm{H}$ atoms, which is a reasonable assumption under $\mathrm{H}$-rich atmosphere CVD conditions. When studying a chemisorbed adsorbate one or two capping $\mathrm{H}$ at the center part of the (0001) surface were replaced by the adsorbate in an appropriate adsorption mode. The energy-minimum structures of the clusters were obtained by geometry optimizations ${ }^{31}$ and the enthalpies and Gibbs free energies at $1300 \mathrm{~K}$ for the optimized geometries were obtained from vibrational normal-coordinate calculations ${ }^{32}$ as described in ref. 33 using the Gaussian09 program. All atoms were allowed to relax in the geometry optimizations. When one $\mathrm{H}$ vacancy was present at the otherwise $\mathrm{H}$-saturated GaN cluster the spin state was a doublet state, whereas for two $\mathrm{H}$ vacancies the triplet state was the state lowest in energy. In case the adsorbate was in a doublet spin state $\left(\right.$ e.g. $\mathrm{CH}_{3}$ ) the dangling bond on the GaN cluster would be saturated so that a singlet state was formed, etc. The lowest-energy state of an isolated $\mathrm{Ga}$ atom was a doublet and that of the $\mathrm{GaCH}_{3}$ molecule a singlet.
For computational convenience, in the identification of transition states and computation of activation energies involving $\mathrm{H}$, Ga and $\mathrm{GaCH}_{3}$ a smaller GaN cluster was used, which consisted of merely $4 \mathrm{GaN}$ units. The numerical values of the activation energies obtained from these small cluster studies will be very approximate, but we consider them as initial guesses that can be further refined by comparison with experiment. The molecular geometries of the large and the small clusters can be seen in Fig. 1. For the molecules containing two $\mathrm{C}$ atoms the activation energies were obtained from the energy profiles when the molecule in a symmetric fashion approached two surface $H$ vacancies at the larger GaN cluster.

In the following, adsorption reaction energies are given in the tables for reactions at a surface where the appropriate number of $\mathrm{H}$ vacancies are already present. The reaction energy for removing one $\mathrm{H}$ atom from the $\mathrm{H}$-saturated $(\mathrm{GaN})_{24}$ cluster is $459 \mathrm{~kJ} \mathrm{~mol}^{-1}$ and the reaction free energy is $272 \mathrm{~kJ} \mathrm{~mol}^{-1}$ (the corresponding values for removing two $\mathrm{H}$ atoms from the same cluster are $918 \mathrm{~kJ} \mathrm{~mol}^{-1}$ and $554 \mathrm{~kJ} \mathrm{~mol}^{-1}$ ).

\subsection{Surface reaction model}

The CFD simulations give the gas phase partial pressure for each species in the bulk flow. To study the possible contribution from each species to the carbon doping, we should analyze the composition at the growth surface, which in a CVD system often is different from the bulk flow composition. One way of estimating this is by calculating impingement rates of the species. The impingement rate, $\Phi$, of species $i$ on the substrate surface can be estimated based on the partial pressure using the expression

$$
\Phi_{i}=\frac{p_{i}}{\sqrt{2 \pi M_{i} R T}}
$$

which is derived from the Maxwell-Boltzmann velocity distribution. $p_{i}$ is the partial pressure of species $i$ which is given directly by the CFD simulation, $M_{i}$ is the molecular mass of the species, $R$ is the molar gas constant and $T$ is the temperature. $\Phi$ has then units of mol m $\mathrm{m}^{-2} \mathrm{~s}^{-1}$.

A common way to describe the surface reaction rate is

$$
\dot{q}=\gamma \cdot \mathrm{e}^{-E_{\mathrm{a}} / R T} \cdot \Phi
$$

where $\Phi$ is the species impingement rate on the surface given by eqn (1), and $\mathrm{e}^{-E_{\mathrm{a}} / R T}$ is the fraction of hits with enough energy
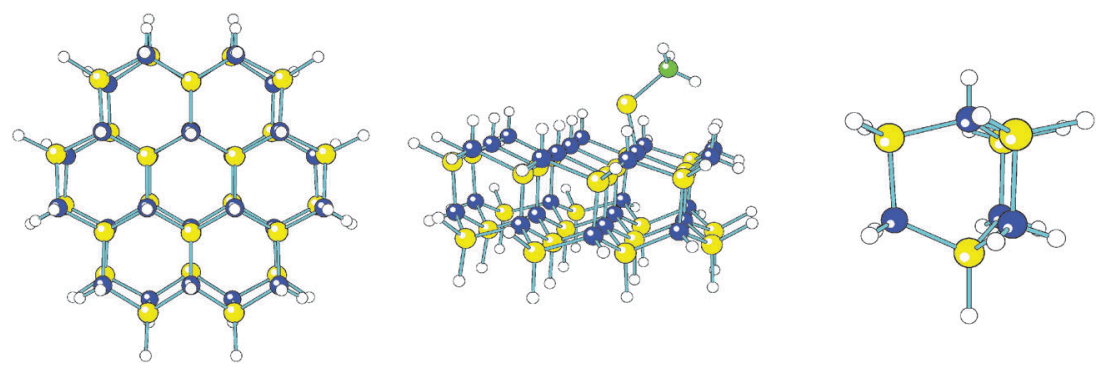

Fig. 1 Molecular geometries of the $\mathrm{H}$-saturated $(\mathrm{GaN})_{24}$ cluster, top view (left), the cluster with an adsorbed $\mathrm{GaCH}_{3}$ molecule at a $\mathrm{H}$ vacancy site, side view (middle), and the smaller $\mathrm{H}$-saturated $(\mathrm{GaN})_{4}$ cluster, side view (right). Yellow: Ga, blue: $\mathrm{N}$, white: $\mathrm{H}$, green: $\mathrm{C}$ atoms. 
for the reaction to occur ( $E_{\mathrm{a}}$ is the activation energy for the reaction). $\gamma$ is the probability that the species impinging on the surface actually will participate in the reaction.

\subsection{Experimental growth}

The growth of epitaxial layers of GaN took place in a horizontal hot-wall CVD system ${ }^{34}$ operating at 50 mbar with a carrier gas mixture of palladium membrane purified hydrogen $\left(\mathrm{H}_{2}\right)$ and nitrogen $\left(\mathrm{N}_{2}\right)$ (99.999\%), at a volumetric $\mathrm{H}_{2} / \mathrm{N}_{2}$ ratio of 6.33 . Growth was done on nominally on-axis $4 \mathrm{H}$-SiC (0001) substrates where first an epitaxial aluminum nitride (AlN) nucleation layer was grown using trimethyl aluminum (TMAl) (SAFC Hightec EpiPure ${ }^{\mathrm{TM}}$ grade) and $\mathrm{NH}_{3}$ (99.9999\%, further purified using a Nanochem ${ }^{\mathbb{R}}$ purifier down to $<1 \mathrm{ppb}$ for important contaminants) with $\mathrm{NH}_{3} / \mathrm{TMAl}=1043$ at $1200{ }^{\circ} \mathrm{C}$. GaN growth was carried out directly on the AlN layer using TMGa (SAFC Hightec EpiPure ${ }^{\mathrm{TM}}$ grade) and $\mathrm{NH}_{3}$.

To study carbon incorporation from TMGa, GaN layers were grown where either temperature or the growth rate was varied during the deposition to produce multiple layers under different CVD conditions and thereby obtaining different carbon concentrations in each layer. The thickness of the individual layers was approximately $200 \mathrm{~nm}$. The growth temperature was varied from $800{ }^{\circ} \mathrm{C}$ to $1050{ }^{\circ} \mathrm{C}$ at a constant $\mathrm{NH}_{3}$ flow rate, with a $\mathrm{NH}_{3} / \mathrm{N}_{2}$ ratio of $2 / 3$, and a TMGa flow giving a $\mathrm{NH}_{3} / \mathrm{TMGa}=$ 625. The growth rate was varied at a constant temperature of $1050{ }^{\circ} \mathrm{C}$ by changing the TMGa flow rate while keeping the $\mathrm{NH}_{3}$ flow constant, giving $\mathrm{NH}_{3} / \mathrm{TMGa}=157-625$.

The multilayers were analyzed by secondary ion mass spectrometry (SIMS), using $\mathrm{Cs}^{+}$as primary ions, to obtain the impurity concentrations. The detection limit for carbon in these specific measurements was $1-2 \times 10^{16} \mathrm{~cm}^{-3}$. All of the SIMS measurements were performed on the center part of the samples.

\section{Results}

\subsection{Gas phase composition}

The gas mixture composition was studied by Computational Fluid Dynamics (CFD). Due to the chemical kinetics, concentrations of different species vary with residence time in the reactor. In Fig. 2 the calculated molefractions of the most abundant species under the standard process conditions $\left(T=1050{ }^{\circ} \mathrm{C}, \mathrm{NH}_{3} / \mathrm{TMGa}=625\right)$ vs. residence time in the CVD reactor are shown. Calculated molefractions under other process conditions $\left(T=1050{ }^{\circ} \mathrm{C}, \mathrm{NH}_{3} / \mathrm{TMGa}=157 ; T=800{ }^{\circ} \mathrm{C}, \mathrm{NH}_{3} /\right.$ $\mathrm{TMGa}=625)$ are presented in the $\mathrm{ESI} \dagger$ for comparison. Even though a large number of elementary reaction steps were included in the kinetic model, it can be concluded that the formation of the main resulting hydrocarbon species can be described by less than 30 reaction steps, illustrated in Fig. 3. As expected, and in line with previous findings, ${ }^{20-22}$ negligible concentrations of the TMGa: $\mathrm{NH}_{3}$ adduct and $\mathrm{Ga}\left(\mathrm{CH}_{3}\right)_{2} \mathrm{NH}_{x}$ compounds were found at all temperatures and flow rates. Instead, the TMGa quickly decomposes in the gas into $\mathrm{GaCH}_{3}$

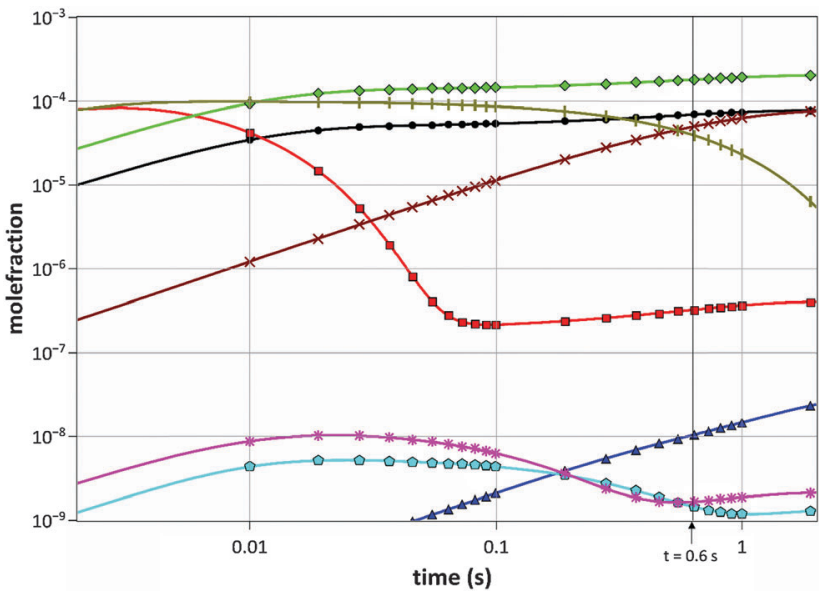

Fig. 2 Calculated molefractions of the most abundant species in the gas phase. $\left(\mathrm{H}_{2}, \mathrm{~N}_{2}\right.$, and $\mathrm{NH}_{3}$ are omitted.) Process conditions: $T=1050{ }^{\circ} \mathrm{C}$,

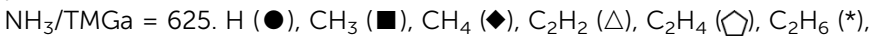
$\mathrm{Ga}(\times), \mathrm{GaCH}_{3}(\mid)$.

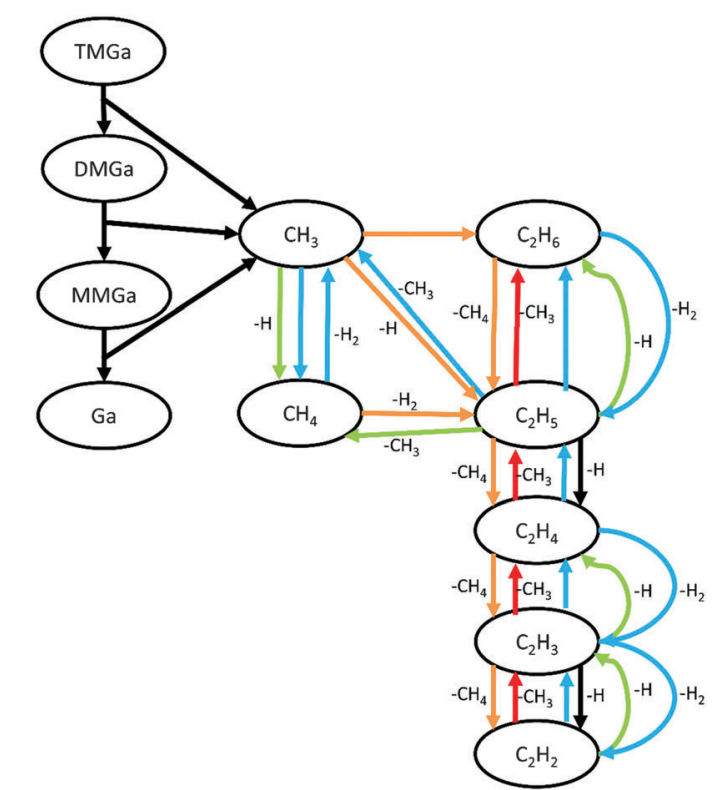

Fig. 3 Decomposition reaction paths for TMGa in the gas phase. Unimolecular reactions are indicated by black arrows. Reaction partners in bimolecular reactions are indicated by $\mathrm{H}$ (blue), $\mathrm{H}_{2}$ (green), $\mathrm{CH}_{3}$ (orange), and $\mathrm{CH}_{4}$ (red).

and two methyl radicals. $\mathrm{GaCH}_{3}$ takes a while longer to decompose, and its concentration starts to drop after about 1 second at $1050{ }^{\circ} \mathrm{C}$ (Fig. 2), but is relatively stable for times $>2$ seconds at temperatures below $900{ }^{\circ} \mathrm{C}$ (see the ESI $\dagger$ ). The methyl radicals are converted into mainly $\mathrm{CH}_{4}$. However, some of them instead combine into $\mathrm{C}_{2} \mathrm{H}_{6}$, which then decomposes to $\mathrm{C}_{2} \mathrm{H}_{4}$ and $\mathrm{C}_{2} \mathrm{H}_{2}$ (Fig. 3). Atomic hydrogen, from splitting of $\mathrm{H}_{2}$ molecules, and reactions between hydrocarbons and $\mathrm{H}_{2}$, has concentration levels of the same order as $\mathrm{GaCH}_{3}$ and $\mathrm{CH}_{4}$, and its concentration is fairly stable after $0.05 \mathrm{~s}$. Notable is also that $\mathrm{C}_{2} \mathrm{H}_{2}$ does not approach a state of equilibrium within the first two seconds. This could be explained by the relatively long chain of reactions 
from $\mathrm{CH}_{3}$ to reach $\mathrm{C}_{2} \mathrm{H}_{2}$ (Fig. 3), and the relatively low reaction rates for converting $\mathrm{C}_{2} \mathrm{H}_{3}$ to $\mathrm{C}_{2} \mathrm{H}_{2}$.

\subsection{Surface reactions and activation energies}

Quantum-chemical calculations were utilized to compute geometries and energies for adsorption of the molecules found to be the most abundant ones in the gas-phase $\left(\mathrm{H}, \mathrm{H}_{2}, \mathrm{Ga}, \mathrm{CH}_{3}\right.$, $\mathrm{GaCH}_{3}, \mathrm{C}_{2} \mathrm{H}_{2}, \mathrm{C}_{2} \mathrm{H}_{4}$ and $\left.\mathrm{C}_{2} \mathrm{H}_{6}\right) . \mathrm{CH}_{4}$ was excluded from the study since it is assumed that its reactivity with the GaN surface is negligible. Calculations were done both at the GaN surface, using the cluster model described in Section 2.2, as well as for the molecules in the gas phase. Electronic energies (i.e. potential energies for the nuclear motions), enthalpies and Gibbs free energies were calculated for these structures. From the energies obtained, the reaction energies and reaction enthalpies were computed for the reactions between the gas phase species and the GaN surface. In addition, activation energies were computed for the relevant reactions.

As pointed out in Section 2.2, adsorption is assumed to take place on a hydrogen terminated surface where one or two "free sites" (i.e. a surface site without the terminating hydrogen atom/atoms) are available for the adsorbing species. Thus, the reaction energies calculated here does not include the removal of surface $H$. The reaction energies to create a single "free" surface site is $459 \mathrm{~kJ} \mathrm{~mol}^{-1}$, and two adjacent "free" surface sites is $918 \mathrm{~kJ} \mathrm{~mol}^{-1}$, respectively.

Atomic Ga adsorbs without activation energy, and the reaction free energy is calculated to be $-304 \mathrm{~kJ} \mathrm{~mol}^{-1} \cdot \mathrm{GaCH}_{3}$ can adsorb either with its $\mathrm{Ga}$ atom or with the methyl group at a single adsorption site (Reactions (2) and (4) in Table 1). In the first case $\mathrm{GaCH}_{3}$ adsorbs with its $\mathrm{Ga}$ atom to a free surface site without activation energy, while keeping its bond to the methyl group. To break the $\mathrm{Ga}-\mathrm{CH}_{3}$ bond when the molecule has adsorbed in this way requires about $147 \mathrm{~kJ} \mathrm{~mol}^{-1}$, as obtained from the calculations, which means that very few of these bonds actually will break at the temperatures used here.

In the second case, when $\mathrm{GaCH}_{3}$ approaches the surface with the methyl group first, the $\mathrm{Ga}-\mathrm{CH}_{3}$ bond will break as the

Table 1 Proposed model for GaN growth and carbon incorporation. (g) indicates a gaseous species, while (ads) indicates a species that is adsorbed on the surface. The values of the reaction probabilities, $\gamma$, are further explained in Section 4

\begin{tabular}{|c|c|c|c|}
\hline Surface reaction & $\begin{array}{l}\text { Reaction } \\
\text { probability, } \gamma\end{array}$ & $\begin{array}{l}\text { Activation } \\
\text { energy, } \\
E_{\mathrm{a}} \\
\left(\mathrm{kJ} \mathrm{mol} \mathrm{mol}^{-1}\right)\end{array}$ & 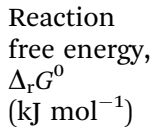 \\
\hline \multicolumn{4}{|l|}{ Growth } \\
\hline 1. $\mathrm{Ga}(\mathrm{g}) \rightarrow \mathrm{Ga}($ ads $)$ & 0.135 & 0 & -304 \\
\hline \multicolumn{4}{|l|}{ Growth and carbon adsorption } \\
\hline 2. $\mathrm{GaCH}_{3}(\mathrm{~g}) \rightarrow \mathrm{GaCH}_{3}(\mathrm{ads})$ & 0.135 & 0 & -112 \\
\hline \multicolumn{4}{|l|}{ Carbon adsorption } \\
\hline 3. $\mathrm{CH}_{3}(\mathrm{~g}) \rightarrow \mathrm{CH}_{3}(\mathrm{ads})$ & 0.135 & 0 & -117 \\
\hline 4. $\mathrm{CH}_{3} \mathrm{Ga}(\mathrm{g}) \rightarrow \mathrm{CH}_{3}(\mathrm{ads})+\mathrm{Ga}(\mathrm{g})$ & 0.135 & 35 & -3.0 \\
\hline 5. $\mathrm{C}_{2} \mathrm{H}_{2}(\mathrm{~g}) \rightarrow \mathrm{C}_{2} \mathrm{H}_{2}$ (ads) & 0.002 & 38 & -270 \\
\hline 6. $\mathrm{C}_{2} \mathrm{H}_{4}(\mathrm{~g}) \rightarrow \mathrm{C}_{2} \mathrm{H}_{4}(\mathrm{ads})$ & 0.002 & 28 & -171 \\
\hline
\end{tabular}

bond between the methyl group and the surface is established (Reaction (4)).

Similarly, $\mathrm{C}_{2} \mathrm{H}_{6}$ could react with the surface in the same way (i.e. with one of its $\mathrm{CH}_{3}$ 's approaching the surface, while breaking off the other $\mathrm{CH}_{3}$ group). This reaction however, has a positive reaction free energy which indicates that the reaction is disfavored, and the activation energy is relatively large, $188 \mathrm{~kJ} \mathrm{~mol}^{-1}$.

There is also a possibility that $\mathrm{GaCH}_{3}$ adsorbs on two adjacent sites (adsorbing with both its $\mathrm{Ga}$ and $\mathrm{C}$ atom at the same time). This reaction is energetically favored (reaction free energy of $-307 \mathrm{~kJ} \mathrm{~mol}^{-1}$ ), assuming there are two adjacent sites available. However, the probability that the molecule actually finds two adjacent vacancies is considered much smaller than the probability that it will find one single vacancy, and thus the contribution from this type of adsorption should be small in comparison to the other two options.

Free methyl radicals are also present in the gas phase for the whole temperature range studied here. The reaction free energy for $\mathrm{CH}_{3}$ adsorption (Reaction (3)) is similar to that of $\mathrm{GaCH}_{3}$ adsorption (Reaction (2)), and the activation energy is taken to be close to zero considering the highly reactive nature of the methyl radical.

At the higher temperatures $\mathrm{C}_{2} \mathrm{H}_{2}, \mathrm{C}_{2} \mathrm{H}_{4}$ and $\mathrm{C}_{2} \mathrm{H}_{6}$ have high enough partial pressures in the gas phase to possibly make a significant contribution to carbon doping. It is assumed that these species will contribute with both their carbon atoms to doping if they adsorb. Adsorption will thus take place when there are two adjacent free sites available. For $\mathrm{C}_{2} \mathrm{H}_{2}$ and $\mathrm{C}_{2} \mathrm{H}_{4}$ the reaction free energies are $-270 \mathrm{~kJ} \mathrm{~mol}^{-1}$ and $-174 \mathrm{~kJ} \mathrm{~mol}^{-1}$, respectively, and the activation energies are $38 \mathrm{~kJ} \mathrm{~mol}^{-1}$ and $28 \mathrm{~kJ} \mathrm{~mol}^{-1}$. When $\mathrm{C}_{2} \mathrm{H}_{6}$ approaches the surface the calculations show that the free sites at the surface will "steal" two of the hydrogen atoms from the molecule, resulting in a fully hydrogen terminated surface, and no carbon incorporation will take place.

The Gibbs free energies and activation energies for the reactions chosen to be relevant in the present study are presented in Table 1 . The values of the reaction probabilities in Table 1 are further explained in Section 4.

\subsection{Experimental results}

Experiments were performed to measure the carbon incorporation with varying temperatures and varying TMGa inlet flow rates. The carbon concentration and thickness (from where the growth rate could be calculated) of each layer were measured by SIMS. The variation in carbon concentration measurements is between $4-11 \%$ (less variation at higher carbon concentration). The error in growth rate measurements is estimated to be less than $5 \%$. The results are presented in Tables 2 and 3 below.

\section{Model of carbon incorporation}

Based on the results presented above, we propose an empirical model for the chemistry of GaN growth and carbon incorporation, where reaction rates are calculated according to eqn (2), taking into account the reactions in Table 1. Adsorption of $\mathrm{NH}_{3}$ 
Table 2 Carbon concentrations, as obtained from SIMS, and corresponding experimental growth rates when varying temperature. $\mathrm{NH}_{3} / \mathrm{TMGa}$ ratio was $625\left(2000 \mathrm{sccm} \mathrm{NH}, 19000 \mathrm{sccm} \mathrm{H} H_{2} \text { and } 3000 \mathrm{sccm} \mathrm{N}\right)_{2}$ ), and the pressure was 50 mbar

\begin{tabular}{llllll}
\hline Temperature $\left({ }^{\circ} \mathrm{C}\right)$ & 800 & 900 & 1000 & 1030 & 1050 \\
\hline Carbon concentration $\left(\mathrm{cm}^{-3}\right)$ & $1.2 \times 10^{20}$ & $4.3 \times 10^{19}$ & $1.9 \times 10^{17}$ & $6.1 \times 10^{16}$ \\
Growth rate $\left(\mu \mathrm{m} \mathrm{h}^{-1}\right)$ & 0.65 & 0.80 & 0.99 & 1.12
\end{tabular}

Table 3 Carbon concentrations, as obtained by SIMS, and corresponding experimental growth rates when varying the inlet $\mathrm{NH}_{3} / \mathrm{TMGa}$ ratio (constant $\mathrm{NH}_{3}$ flow rate of $2000 \mathrm{sccm}$ ). The temperature was $1050{ }^{\circ} \mathrm{C}$ and the pressure $50 \mathrm{mbar}$

\begin{tabular}{lllllll}
\hline $\mathrm{NH}_{3} / \mathrm{TMGa}$ ratio & 625 & 418 & 314 & 251 & 209 & 179 \\
\hline Carbon conc. $\left(\mathrm{cm}^{-3}\right)$ & $6.0 \times 10^{16}$ & $8.1 \times 10^{16}$ & $1.2 \times 10^{17}$ & $1.7 \times 10^{17}$ & $2.4 \times 10^{17}$ & $3.3 \times 10^{17}$ \\
Growth rate $\left(\mu \mathrm{m} \mathrm{h}^{-1}\right)$ & 1.29 & 1.32 & 1.83 & 2.38 & 2.82 & 3.17
\end{tabular}

is not included in the model: it is assumed that the growth is limited by supply of Ga.

\subsection{Calculations of growth rate}

It is crucial that the model can give reasonably accurate growth rates if it shall be used to predict doping concentrations. The $\mathrm{Ga}$ that contributes to growth comes either from atomic $\mathrm{Ga}$ or $\mathrm{GaCH}_{3}$. All other Ga-containing molecules have too low partial pressures in the gas phase to make any significant contribution. $\mathrm{GaCH}_{3}$ can adsorb either with its $\mathrm{Ga}$ atom or with its $\mathrm{C}$ atom in the methyl group. When it adsorbs with its $\mathrm{C}$ atom, the $\mathrm{Ga}-\mathrm{CH}_{3}$ bond will break, resulting in a free Ga atom in the gas phase. This $\mathrm{Ga}$ atom is then available for adsorption on another surface site. It seems reasonable to assume that the probability for either orientation of the $\mathrm{GaCH}_{3}$ molecule is equal, so that $50 \%$ undergoes reaction (2) and the other $50 \%$ undergoes reaction (4). Since the $\mathrm{Ga}$ atoms resulting from reaction (4) are also available for adsorption, these are included as well when calculating the growth rates.

Thus, the growth rate, $\dot{R}_{\mathrm{g}}$, is calculated by

$$
\dot{R}_{\mathrm{g}}=\dot{q}_{\mathrm{Ga}} \frac{M_{\mathrm{GaN}}}{\rho_{\mathrm{GaN}}}
$$

where $\dot{q}_{\mathrm{Ga}}=\dot{q}_{\mathrm{R} 1}+\dot{q}_{\mathrm{R} 2}+\dot{q}_{\mathrm{R} 4}, M_{\mathrm{GaN}}$ is the molar mass of GaN, $\rho_{\mathrm{GaN}}$ is the GaN density, and $\dot{q}_{R i}$ is calculated using eqn (2). The probability parameter, $\gamma$, was determined by comparing calculated growth rates against experiments. As mentioned in Section $2, \gamma$ is a measure of the probability that a species impinging on the surface actually will participate in an adsorption reaction. Thus, this parameter could be related to the fraction of sites available for adsorption, and here it could also be assumed to include the depletion of precursors upstream of the deposition area, which decreases the amount of available molecules for growth. A value of $\gamma=0.135$ was chosen for the reactions involving $\mathrm{Ga}$, to give reasonably good agreement in growth rates, as compared to experimental data. This value was also used for reaction (3), where $\mathrm{CH}_{3}$ adsorbs directly on the surface, since it seems reasonable to assume that the probability to find a single surface adsorption site would be equal regardless of which molecule that adsorbs. The calculated and measured growth rates are compared in Fig. 4 and 5 below.

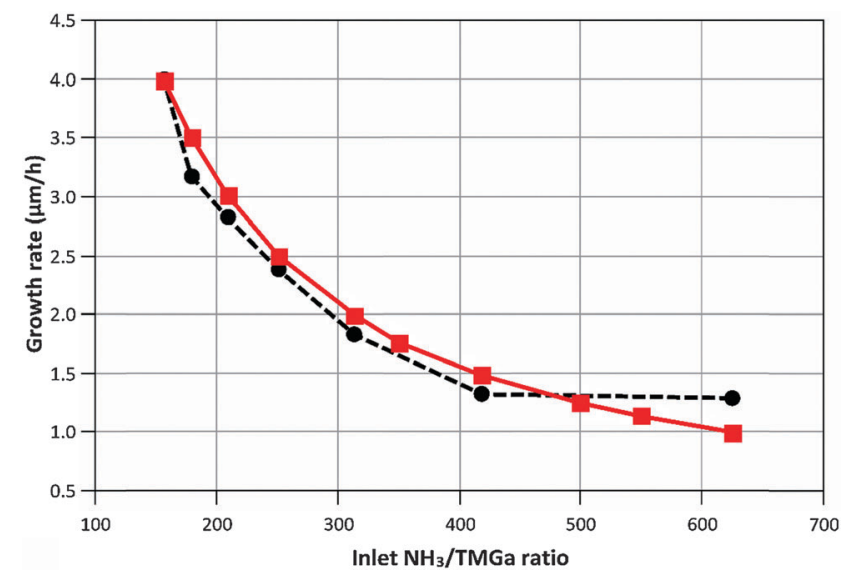

Fig. 4 Calculated (- - - ) and measured (- -) growth rates when varying the inlet $\mathrm{NH}_{3} / \mathrm{TMGa}$ ratio at constant $\mathrm{NH}_{3}$ flow $(2000 \mathrm{sccm})$. Process temperature is $1050{ }^{\circ} \mathrm{C}$.

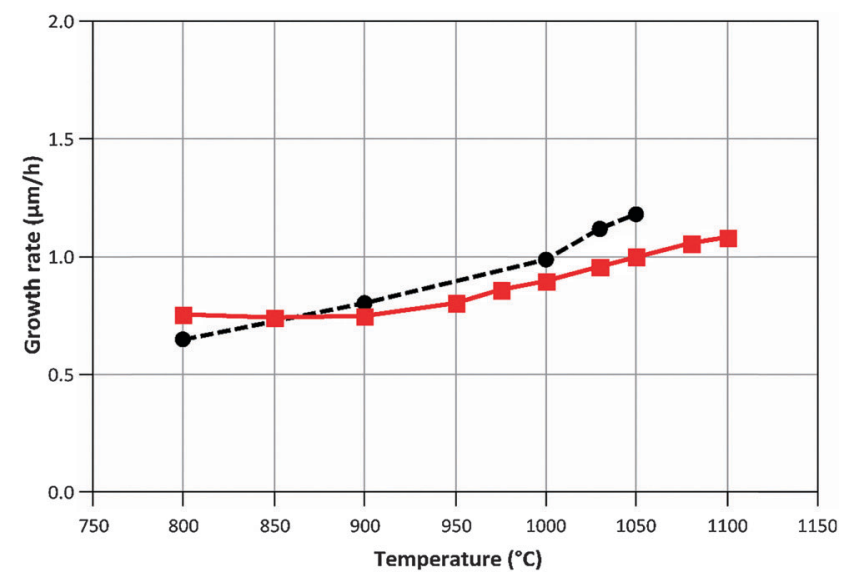

Fig. 5 Calculated (- - - ) and measured (- - ) growth rates when varying the process temperature. $\mathrm{NH}_{3} / \mathrm{TMGa}$ ratio $=625$.

The model predicts a change in relative contribution to the growth from $\mathrm{GaCH}_{3}$ and atomic $\mathrm{Ga}$, respectively, with temperature. The relative contribution from $\mathrm{GaCH}_{3}$ changes from $99.1 \%$ at $800{ }^{\circ} \mathrm{C}$ to $27.8 \%$ at $1050{ }^{\circ} \mathrm{C}$. This change could be one explanation to the improved morphology and structural quality obtained at higher temperatures, as $\mathrm{CH}_{3}$ has been 
suggested to degrade both these properties of GaN epitaxial layers. $^{8}$

\subsection{Calculations of doping concentration}

The doping concentration (number density), $n_{c}$, is the fraction of $\mathrm{C}$ atoms in the GaN lattice.

$$
n_{\mathrm{C}}=\frac{\dot{q}_{\mathrm{C}}}{\dot{q}_{\mathrm{Ga}}} n_{\mathrm{Ga}}
$$

where $n_{\mathrm{Ga}}$ is the number density of Ga atoms in the GaN lattice.

$$
n_{\mathrm{Ga}}=\frac{\rho_{\mathrm{GaN}}}{M_{\mathrm{GaN}}} N_{\mathrm{A}}
$$

where $N_{\mathrm{A}}$ is Avogadro's constant. $\dot{q}_{\mathrm{Ga}}$ is the same as in eqn (3), and thus eqn (4) can be re-written using the growth rate $\dot{R}_{\mathrm{g}}$ so that

$$
n_{\mathrm{C}}=\frac{\dot{q}_{\mathrm{C}}}{\dot{R}_{\mathrm{g}}} N_{\mathrm{A}}
$$

This means that as the growth rate increases, the doping concentration would decrease. However, since Ga and C adsorb together via $\mathrm{GaCH}_{3}$, the doping concentration could actually remain constant with increasing growth rate.

When examining the measured doping variation with temperature it is observed that there is a large drop in doping concentration of two orders of magnitude between $900{ }^{\circ} \mathrm{C}$ and $1000{ }^{\circ} \mathrm{C}$ (see Table 2). Looking at the simulated concentrations of different carbon containing species in the gas phase we find no obvious reason for this large drop. It is further observed that if all carbon atoms that follow $\mathrm{Ga}$ to the surface via $\mathrm{GaCH}_{3}$ would be incorporated into the material, the doping level would be at least two orders of magnitude too high in the lower part of the temperature range, and about 5 orders of magnitude too high at the higher temperatures. Fig. S6 in the ESI $\uparrow$ shows the contribution from the different molecules $v s$. temperature. These results strongly suggest that there must be an efficient mechanism that removes carbon from the surface before it is incorporated into the material. This is consistent with previous findings. ${ }^{4,35}$ In the literature some mechanisms have been suggested for the removal of carbon from the GaN surface, such as a rehydrogenation process where atomic hydrogen reacts with carbon at the surface, and then desorb as methyl or methane, or blocking of surface sites by $\mathrm{H}$ atoms. Lam et al. estimated the activation energy for direct desorption of methyl radicals from the GaN surface to be about $171 \mathrm{~kJ} \mathrm{~mol}^{-1} \cdot^{36}$ They also found that significant amounts of methane may be produced from reactions involving adsorbed methyl and hydrogen atoms. Koleske et al. estimated an activation energy of about $154 \mathrm{~kJ} \mathrm{~mol}^{-1}$ for the carbon removal at temperatures between $650{ }^{\circ} \mathrm{C}$ and $1100{ }^{\circ} \mathrm{C} .{ }^{4}$

Assuming the gas phase reaction mechanism we have used here is correct, it is mainly carbon coming from $\mathrm{GaCH}_{3}$ and $\mathrm{CH}_{3}$ that should be removed (or not adsorbed at all) for the modeling results to agree with experimental data. When calculating reaction energies for four possible reactions for the removal of adsorbed methyl (Table 4) it can be seen that all of them are exothermic and therefore energetically favored. It can also be concluded that the
Table 4 Possible methyl removal reactions, and their respective calculated reaction energies

\begin{tabular}{lll}
\hline & & \\
& Removal of methyl groups & \multicolumn{2}{c}{$\begin{array}{l}\text { Reaction energy, } \\
\Delta E\left(\mathrm{~kJ} \mathrm{~mol}^{-1}\right)\end{array}$} \\
\hline 7. & $\mathrm{GaCH}_{3}(\mathrm{ads})+\mathrm{H}(\mathrm{g}) \rightarrow \mathrm{Ga}(\mathrm{ads})+\mathrm{CH}_{4}(\mathrm{~g})$ & -328 \\
8. & $\mathrm{GaCH}_{3}(\mathrm{ads})+\mathrm{CH}_{3}(\mathrm{~g}) \rightarrow \mathrm{Ga}(\mathrm{ads})+\mathrm{C}_{2} \mathrm{H}_{6}(\mathrm{~g})$ & -255 \\
9. & $\mathrm{CH}_{3}(\mathrm{ads})+\mathrm{H}(\mathrm{g}) \rightarrow \mathrm{CH}_{4}(\mathrm{~g})$ & -80 \\
10. & $\mathrm{CH}_{3}(\mathrm{ads})+\mathrm{CH}_{3}(\mathrm{~g}) \rightarrow \mathrm{C}_{2} \mathrm{H}_{6}(\mathrm{~g})$ & -6 \\
\hline
\end{tabular}

removal of the $\mathrm{CH}_{3}$ group from adsorbed $\mathrm{GaCH}_{3}$ with the aid of atomic $\mathrm{H}$ or $\mathrm{CH}_{3}$ (reactions (7) and (8)) in the gas phase is much more favorable than the corresponding removal of adsorbed $\mathrm{CH}_{3}$ from the surface (reactions (9) and (10)).

We have here listed some of the more likely reaction steps for removing $\mathrm{CH}_{3}$ from the surface of the growing GaN crystal. However, we believe that the process is more complex than this, but it is beyond the scope of this paper to go any further in the surface reaction modeling at this point. Instead we assume that we could describe the removal of methyl with one single reaction step, where the reaction rate is given by an Arrhenius expression. By analyzing how many of the methyl groups that needs to be removed, for the modeling results to agree with experimental findings, we find that this single reaction step should have an activation energy of $0.26 \mathrm{~kJ} \mathrm{~mol}^{-1}$. If we on the other hand would assume that every $\mathrm{CH}_{3}$ in the $\mathrm{GaCH}_{3}$ molecules that adsorb immediately are removed, as soon as adsorption has taken place (e.g. with the aid of $\mathrm{H}$ or gaseous $\mathrm{CH}_{3}$ reactions (7) and (8)), then some of the remaining $\mathrm{CH}_{3}$ 's must still be removed. The activation energy for removing these remaining methyls should then be $9.49 \mathrm{~kJ} \mathrm{~mol}^{-1}$, to match the model with experiments. The assumption that all of the $\mathrm{CH}_{3}$ 's in the adsorbed $\mathrm{GaCH}_{3}$ are removed could be motivated by the relatively low reaction energies for those reactions.

Adding either of these two desorption reaction mechanisms to the model greatly improves the model's agreement with experimental data. It is also noted that with this desorption mechanism included, all of the $\mathrm{CH}_{3}$ 's will be removed at temperatures above $950{ }^{\circ} \mathrm{C}$ under the conditions we use. At higher temperatures $\left(>950{ }^{\circ} \mathrm{C}\right.$ ) the doping concentration levels are well predicted taking only $\mathrm{C}_{2} \mathrm{H}_{2}$ and $\mathrm{C}_{2} \mathrm{H}_{4}$ into account as carbon contributors. For the reactions involving $\mathrm{C}_{2} \mathrm{H}_{2}$ and $\mathrm{C}_{2} \mathrm{H}_{4}$, a value of $\gamma=0.002$ was used. The value was determined by trial-and-error to achieve a good agreement with experimental data when varying the $\mathrm{NH}_{3} / \mathrm{TMGa}$ inlet ratio, but it seems to give good results also when the temperature varies between $1000{ }^{\circ} \mathrm{C}-1100{ }^{\circ} \mathrm{C}$. The $\mathrm{C}_{2} \mathrm{H}_{2}$ and $\mathrm{C}_{2} \mathrm{H}_{4}$ molecules adsorb on two surface sites simultaneously, and it would be safe to assume that the probability to find two adjacent free surface sites is much less than finding a single site. Thus, the value of $\gamma$ seems reasonable.

Calculated and measured doping concentrations are compared in Fig. 6 and 7 below.

\section{Discussion}

The proposed model mimics the carbon doping concentrations well under the process conditions studied. At low temperatures 


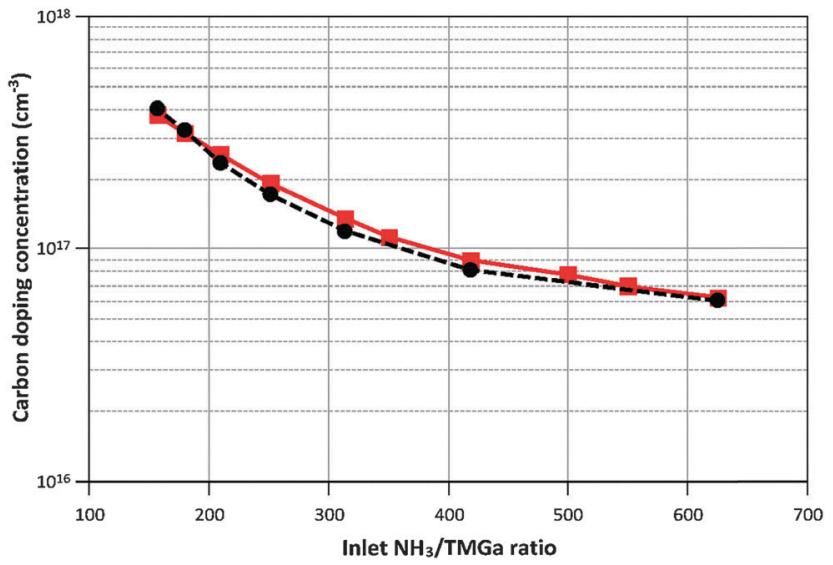

Fig. 6 Calculated (- - ) and measured (- -) carbon doping concentrations when varying the $\mathrm{NH}_{3} / \mathrm{TMGa}$ ratio at constant $\mathrm{NH}_{3}$ flow $(2000 \mathrm{sccm}$ ) and $T=1050^{\circ} \mathrm{C}$.

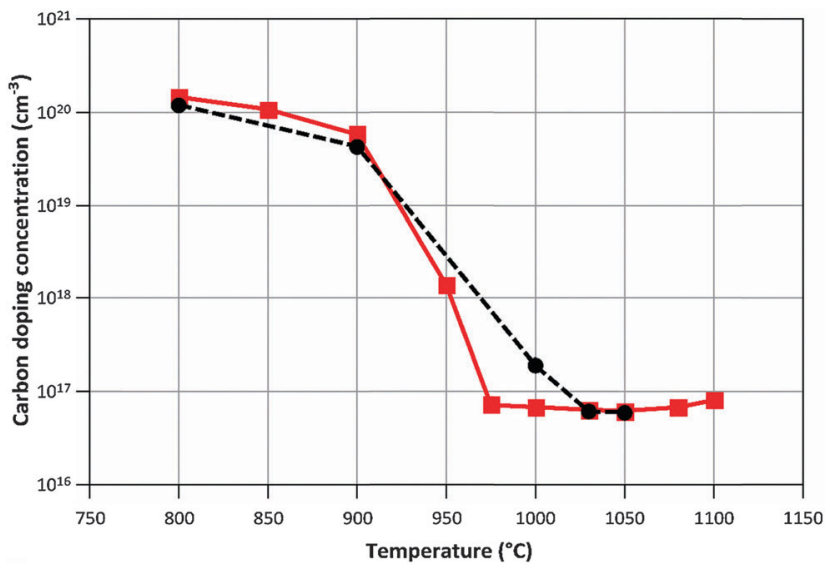

Fig. 7 Calculated (- - ) and measured (- - ) carbon doping concentrations when varying the process temperature. $\mathrm{NH}_{3} / \mathrm{TMGa}$ ratio $=625$.

carbon is supplied mainly via $\mathrm{GaCH}_{3}$ molecules, which bind to the surface with their $\mathrm{Ga}$ atoms, leaving the $\mathrm{Ga}-\mathrm{CH}_{3}$ bond intact. The $\mathrm{Ga}$ in these $\mathrm{GaCH}_{3}$ molecules are needed to achieve a correct prediction of growth rates over the temperature range studied. It is however evident from the obtained results that most of the carbon from the methyl groups must desorb from the surface to have doping concentration levels in line with measured data. The amount of desorbed methyl ranges from about $99.7 \%$ at $800{ }^{\circ} \mathrm{C}$ to $100 \%$ at temperatures above $1000{ }^{\circ} \mathrm{C}$. According to the quantum chemical calculations, the $\mathrm{Ga}-\mathrm{CH}_{3}$ bond is hard to break, and therefore the carbon drawn to the surface by the $\mathrm{GaCH}_{3}$ molecule will stay there if it is not removed by some other reaction mechanism. In the proposed model we suggest that the removal of $\mathrm{CH}_{3}$ could take place through the reaction between a hydrogen atom in the gas and an adsorbed methyl group, eventually forming methane, or through reaction between a $\mathrm{CH}_{3}$ radical in the gas and an adsorbed methyl group, forming $\mathrm{C}_{2} \mathrm{H}_{6}$. These reactions are exothermic and therefore energetically favored. There could, of course, be some other mechanism or a combination of several reactions responsible for a lower carbon incorporation, compared to the modeling results. Either way, it can be concluded that, if a good correlation with measured values should be obtained, some desorption mechanism is needed. Another explanation could be that the amount of $\mathrm{GaCH}_{3}$ in the gasphase is overpredicted by the kinetic model, and that we instead would have more atomic Ga contributing to the growth. This would initially lead to more $\mathrm{CH}_{3}$ in the gas, but since a lot of these molecules will be converted to $\mathrm{CH}_{4}$, the effect of an easier breakage of the $\mathrm{GaCH}_{3}$ molecule will be less active carbon containing molecules contributing to the doping. However, at the moment we find no reason to distrust the gas-phase reaction rates for TMGa decomposition, obtained by Sengupta et al., ${ }^{16}$ which were evaluated under relevant process conditions.

At higher temperatures, $\mathrm{C}_{2} \mathrm{H}_{2}$ and $\mathrm{C}_{2} \mathrm{H}_{4}$ are the main species contributing to the carbon doping. This is the result of increased production rates of these molecules in the gas, and the fact that $\mathrm{CH}_{3}$ is removed completely from the GaN surface at higher temperatures, using the assumptions made in the model. With our model, the change in carbon doping concentrations with varying TMGa inlet concentrations and with varying temperatures is well predicted. It should be noted that if $\mathrm{CH}_{3}$ would not be removed completely at the higher temperatures, the prediction of the variation in carbon doping concentration with TMGa inlet concentration would not be as accurate as is obtained now. Thus, we can conclude that there is a relatively rapid switch at about $1000{ }^{\circ} \mathrm{C}$, from $\mathrm{CH}_{3}$ to $\mathrm{C}_{2} \mathrm{H}_{x}$ as the most important carbon source.

It should also be noted that to obtain high crystalline quality of the GaN layers, the optimal growth temperature is above $1000{ }^{\circ} \mathrm{C}$, and that lower temperatures often yield layers with high dislocation densities. This agrees well with our findings here, since it has been suggested by others that high amounts of $\mathrm{CH}_{3}$ could degrade the GaN morphology and structural quality.

\section{Conclusion}

The model for carbon incorporation into GaN epitaxial layers presented here predicts the carbon doping levels very well at the most relevant temperatures and precursor flow rates. Since the methodology is based on ab initio quantum chemical calculations, and geometry independent calculations of the gas-phase composition, the constructed model is essentially reactor independent and it should therefore be possible to use it for any type of GaN CVD equipment.

The contribution of gallium to the GaN layer shifts from $\mathrm{GaCH}_{3}$ at low temperatures to pure Ga at higher temperatures. In the same way there is a shift in carbon contribution, from $\mathrm{CH}_{3}$ at low temperatures to $\mathrm{C}_{2} \mathrm{H}_{x}$ at higher temperatures.

\section{Acknowledgements}

Financial support from the Swedish Foundation for Strategic Research (SSF) and the Swedish Defence Material Administration (FMV) is gratefully acknowledged. The Swedish National 
Supercomputer Centre (NSC) and SNIC are acknowledged for providing computational resources.

\section{References}

1 M. J. Uren, IEEE Trans. Electron Devices, 2012, 59, 3327.

2 A. Armstrong, A. R. Arehart, B. Moran, S. P. DenBaars, U. K. Mishra, J. S. Speck and S. A. Ringel, Appl. Phys. Lett., 2004, 84, 374.

3 A. Zado, E. Tschumak, J. W. Gerlach, K. Lischka and D. J. As, J. Cryst. Growth, 2011, 323, 88.

4 D. D. Koleske, A. E. Wickenden, R. L. Henry and M. E. Twigg, J. Cryst. Growth, 2002, 242, 55.

5 A. Stegmüller, P. Rosenow and R. Tonner, Phys. Chem. Chem. Phys., 2014, 16, 17018.

6 G. Parish, S. Keller, S. P. Denbaars and U. K. Mishra, J. Electron. Mater., 2000, 29, 15.

7 A. Ishibashi, H. Takeishi, M. Mannoh, Y. Yabuuchi and Y. Ban, J. Electron. Mater., 1995, 25, 799.

8 X. Li, Ö. Danielsson, H. Pedersen, E. Janzén and U. Forsberg, J. Vac. Sci. Technol., B: Nanotechnol. Microelectron.: Mater., Process., Meas., Phenom., 2015, 33, 021208.

9 W. Tsang and R. F. Hampson, J. Phys. Chem. Ref. Data, 1986, 15, 1087.

10 W. Tsang, J. Phys. Chem. Ref. Data, 1988, 17, 887.

11 W. Tsang, J. Phys. Chem. Ref. Data, 1990, 19, 1.

12 W. Tsang, J. Phys. Chem. Ref. Data, 1991, 21, 20.

13 D. L. Baulch, C. J. Cobos, R. A. Cox, C. Esser, P. Frank, T. Just, J. A. Kerr, M. J. Pilling, J. Troe, R. W. Walker and J. Warnatz, J. Phys. Chem. Ref. Data, 1992, 21, 411.

14 D. L. Baulch, C. J. Cobos, R. A. Cox, P. Frank, G. Hayman, T. Just, J. A. Kerr, T. Murrells, M. J. Pilling, J. Troe, R. W. Walker and J. Warnatz, J. Phys. Chem. Ref. Data, 1994, 23, 847.

15 D. L. Baulch, C. T. Bowman, C. J. Cobos, R. A. Cox, T. Just, J. A. Kerr, M. J. Pilling, D. Stocker, J. Troe, W. Tsang, R. W. Walker and J. Warnatz, J. Phys. Chem. Ref. Data, 2005, 34, 757.

16 D. Sengupta, S. Mazumder, W. Kuykendall and S. A. Lowry, J. Cryst. Growth, 2005, 279, 369.

17 A. Thon and T. F. Kuech, Appl. Phys. Lett., 1996, 69, 55.

18 S. A. Safvi, J. M. Redwing, M. A. Tischler and T. F. Kuech, J. Electrochem. Soc., 1997, 144, 1789.

19 T. G. Mihopoulos, V. Gupta and K. F. Jensen, J. Cryst. Growth, 1998, 195, 733.

20 U. Bergmann, V. Reimer and B. Atakan, Phys. Chem. Chem. Phys., 1999, 1, 5593.

21 J. Schäfer, A. Simons, J. Wolfrum and R. A. Fischer, Chem. Phys. Lett., 2000, 319, 477.
22 D. Sengupta, J. Phys. Chem. B, 2003, 107, 291.

23 R. S. Zhu, R. Q. Zhang and K. S. Chan, Chem. Phys. Lett., 2000, 320, 561.

24 R. B. Bird, W. E. Stewart and E. N. Lightfoot, Transport Phenomena, New York, Wiley, 2007.

25 M. J. Frisch, G. W. Trucks, H. B. Schlegel, G. E. Scuseria, M. A. Robb, J. R. Cheeseman, G. Scalmani, V. Barone, B. Mennucci, G. A. Petersson, H. Nakatsuji, M. Caricato, X. Li, H. P. Hratchian, A. F. Izmaylov, J. Bloino, G. Zheng, J. L. Sonnenberg, M. Hada, M. Ehara, K. Toyota, R. Fukuda, J. Hasegawa, M. Ishida, T. Nakajima, Y. Honda, O. Kitao, H. Nakai, T. Vreven, J. A. J. Montgomery, J. E. Peralta, F. Ogliaro, M. Bearpark, J. J. Heyd, E. Brothers, K. N. Kudin, V. N. Staroverov, R. Kobayashi, J. Normand, K. Raghavachari, A. Rendell, J. C. Burant, S. S. Iyengar, J. Tomasi, M. Cossi, N. Rega, J. M. Millam, M. Klene, J. E. Knox, J. B. Cross, V. Bakken, C. Adamo, J. Jaramillo, R. Gomperts, R. E. Stratmann, O. Yazyev, A. J. Austin, R. Cammi, C. Pomelli, J. W. Ochterski, R. L. Martin, K. Morokuma, V. G. Zakrzewski, G. A. Voth, P. Salvador, J. J. Dannenberg, S. Dapprich, A. D. Daniels, Ö. Farkas, J. B. Foresman, J. V. Ortiz, J. Cioslowski and D. J. Fox, Gaussian 09, Revision D.01, Wallingford CT, Gaussian, Inc., 2009.

26 A. D. Becke, J. Chem. Phys., 1993, 98, 5648.

27 V. A. Rassolov, M. A. Ratner, J. A. Pople, P. C. Redfern and L. A. Curtiss, J. Comput. Chem., 2001, 22, 976.

28 B. Brena and L. Ojamäe, J. Phys. Chem. C, 2008, 112, 13516. 29 M. Kula and L. Ojamäe, Int. J. Quantum Chem., 2012, 112, 1796.

30 W. Paszkowicz, S. Podsiadlo and R. Minikayev, J. Alloys Compd., 2004, 382, 100.

31 C. Peng, P. Y. Ayala, H. B. Schlegel and M. J. Frisch, J. Comput. Chem., 1996, 17, 49; X. Li and M. J. Frisch, J. Chem. Theory Comput., 2006, 2, 835.

32 E. B. Wilson, Jr., Phys. Rev., 1934, 45, 706; E. B. Wilson, Jr., C. Decius and P. C. Cross, Molecular Vibrations, McGraw-Hill, New York, 1955.

33 D. A. McQuarrie and J. D. Simon, Molecular Thermodynamics, University Science Books, 1999.

34 U. Forsberg, A. Lundskog, A. Kakanakova-Georgieva, R. Ciechonski and E. Janzén, J. Cryst. Growth, 2009, 311, 3007.

35 O. Ambacher, M. S. Brandt, R. Dimitrov, T. Metzger, M. Stutzmann, R. A. Fischer, A. Miehr, A. Bergmaier and G. Dollinger, J. Vac. Sci. Technol., B: Microelectron. Nanometer Struct.-Process., Meas., Phenom., 1996, 14, 3532.

36 H.-T. Lam and J. M. Vohs, Surf. Sci., 1999, 426, 199. 